\title{
Determining the source and associated Fe mineralogy of African dust transported to Cayenne, French Guiana
}

\author{
CASSANDRA J. GASTON ${ }^{1}$, ANNE E. BARKLEY ${ }^{2}$; Ali
} POURMAND ${ }^{3}$; ARASH SHARIFI ${ }^{4}$, AMANDA M. OEHLERT ${ }^{5}$; RAVI KUKKADAPU ${ }^{6}$, MARK BOWDEN ${ }^{7}$, KATHY PANECHOU $^{8}$; JOSEPH M. PROSPERO ${ }^{9}$, ANDREW P. AULT ${ }^{10}$

${ }^{1}$ University of Miami; cgaston@rsmas.miami.edu

${ }^{2}$ University of Miami; abarkley@rsmas.miami.edu

3nniversity of Miami; apourmand@rsmas.miami.edu

${ }^{4}$ University of Miami; osharifi@rsmas.miami.edu

${ }^{5}$ University of Miami; aoehlert@rsmas.miami.edu

${ }^{6}$ Pacific Northwest National Laboratory; ravi.kukkadapu@pnnl.gov

${ }^{7}$ Pacific Northwest National Laboratory; mark.bowden@pnnl.gov

${ }^{8}$ ATMO-Guyane; k.panechou@atmo-guyane.org

${ }^{9}$ University of Miami; jprospero@rsmas.miami.edu

${ }^{10}$ University of Michigan; aulta@umich.edu

The soil in the Amazon Basin and water in the Tropical Atlantic Ocean are depleted of nutrients such as iron $(\mathrm{Fe})$. Atmospheric deposition of nutrients from African dust has been shown to replenish these nutrients, which could increase primary productivity in both ecosystems. Fe mineralogy and oxidation phase associated with transported African dust have not been well studied despite being predictors of $\mathrm{Fe}$ bioavailability. Also, identifying the source region of dust transport within the Sahara can aid in understanding $\mathrm{Fe}$ mineralogy. In this work, we characterize two years (2014 and 2016) of transported African dust that was collected in Cayenne, French Guiana. Using radiogenic isotopes $(\mathrm{Nd}, \mathrm{Sr}$, $\mathrm{Hf}$, and $\mathrm{Pb}$ ), we identify a region of western Africa as a major source of transported African dust to Cayenne from December to April in both years. We also use Mössbauer spectroscopy and X-ray Diffraction (XRD) to determine the oxidation state and mineralogy of $\mathrm{Fe}$ that is transported to Cayenne. We find that dust and $\mathrm{Fe}$ mineralogy varies by season and included hematite, goethite, and small amounts of $\mathrm{Fe}(\mathrm{II})$, which is the most soluble form of $\mathrm{Fe}$ and has implications for Fe bioavailabilty in the ocean and Amazon. 